\title{
The concept of "mentoring" as one of the main platforms for the disclosure of students' professional competencies
}

\author{
Evgenia Krasnova $^{1, *}$ and Natalya Mamchits ${ }^{1}$ \\ ${ }^{1}$ Don State Technical University, 1, Gagarina, sq., 344003, Rostov-on-Don, Russia
}

\begin{abstract}
The article considers the concept of professional development of mentoring in higher education institutions. The relevance of this study is to form a closer environment of interaction between students with each other and with the teacher, who points out the necessary professional competencies and forms skills for further cooperation with the employer. The article focuses on two main mentoring platforms: "student-student" and "teacher-student". The analysis of the platforms ' participants` portraits, their interaction for the formation of professional competencies of students is carried out. A general strategy for building work for the two mentioned platforms is proposed. The positive and negative factors of these platforms are identified, effective methods, tools and forms of professional development of the student are proposed. Conclusions about the correct and logical organization of the mentoring platform are formulated.
\end{abstract}

\section{Introduction}

In the age of digital technologies, the influence of mass media on society, distance education, the question of the formation and disclosure of professional competencies of students for further employment becomes very acute [16]. The concept of "becoming" in the dictionary of social pedagogy is revealed as the acquisition of new features and forms in the process of professional self-realization. Currently, the topic of mentoring in education is one of the central points in the national project "Education" (including the federal projects "Modern School", "Success of every child", "Teacher of the Future", "Social elevators for everyone", "Young Professionals"). Thus, the federal project "Modern School" contains a target indicator: by the end of 2024, at least $70 \%$ of students of general education organizations will be involved in various forms of support and mentoring [1] .

In the higher education system, in addition to the traditional forms of training, lectures, seminars, practical classes, quite a lot of approaches are used, one of which is mentoring. In addition to direct counseling, there are such it's forms as curatorship, tutoring, coaching, and mentoring.

In this article, we consider such a method of organizing the educational process as mentoring, which is common mainly in the business environment, but is also quite applicable in the field of education. This method has been used intuitively for a long time, not formally,

\footnotetext{
* Corresponding author: krasnova07@inbox.ru
} 
but rather on an "intuitive level", assigning the role of mentor to the curators, and they, in turn, to the monitor [12].

The relevance of the article is due to the fact that the main stages of interaction between process participants are considered and analyzed for a more structured understanding of how to clearly and logically explain professional competencies and at the same time create a quality product.

\section{Review of scientific sources}

In the leading universities of the world, mentoring has been widespread for a long time, but attention to this platform began to be paid on around the mid-90s of the last century, when it became clear that a properly, step-by-step mentoring process is effective and contributes more to a faster and deeper disclosure of students' professional competencies. The state authorities of such countries as the United States, Spain, and Italy strive to stimulate it and to develop it from all sides. For example, in the United States in 1996, the Presidential Award for Excellence in Science, Mathematics and Engineering Mentoring was established [10].

The term "mentoring" means "edification, teaching". A mentor is a specialist who has established himself in his professional field and is ready to provide mentoring to his ward. Scientists who reveal the essence of this process, note a non-directive style of communication, and carried out rather as a collaboration of a junior and senior colleague, actually bringing the mentor to a new type of educational process.

A.V. Khutorsky in his research distinguishes three types of classes according to the form of their organization: individual, collective-group, individual-collective. Under the proposed classification mentoring should be attributed to the group of individual lessons. But in practice, different forms of implementation of this method are possible [8].

Currently, mentoring refers to a special type of relationship between a specialist with more profound knowledge, professional and life experience (mentor), and a specialist with less knowledge and experience (ward, student), in the process of which the mentor helps to reveal basic professional knowledge and experience, develop practical skills and the necessary professional and personal qualities, socially adapt to the profession, develop high standards of behavior and commitment to moral values [2]. We should not underestimate the psychological aspects of all participants in the process, but this paper does not consider this factor.

Mentoring is a kind of transfer that helps the future specialist to adapt to a new role, effectively carry out professional activities and cultivate a commitment to high professional standards [11].

It should be emphasized that one of the main differences between mentoring and counseling is that mentoring encourages students to self-development, to independently solve professional problems, to find ways to quickly adapt to the profession and the team.

A study of Russian universities in 2003 showed that in Russian higher education institutions there is also a practice of counseling young teachers, which, only to a certain extent, can be compared with the practice of mentoring. According to this study, $45.3 \%$ of departments organize counseling (each young teacher has a mentor - a more experienced employee), $39.9 \%$ of departments of all young teachers are supervised by the head, $9.6 \%$ of departments of young teachers themselves, through trials and errors, gain experience". The presence of mentoring systems or programs in Russian universities has not been established [3]. 


\section{Methods of research}

Theoretical and empirical methods of cognition were used in the work: methods of retrospective analysis of materials, analysis of literature, methods of analogy and comparison, the method of feedback.

It should be emphasized that mentoring is the subject of training in professional education.

\section{Results and discussion}

There are five main mentoring models, (student-student; student-teacher; student-employer; high school student; teacher-employer), but in the framework of our paper, we will take a closer look at such models as "teacher - student", "student-student", we will make a psychological portrait of both participants, as well as identify the negative and positive aspects of this cooperation.

Already initially, in such models, it is established who is the mentor and who is the ward (especially for the model, "student-student")

Student-to-student mentoring platform.

This format of the platform involves partner mentoring. It is interesting that sometimes students who are younger in age can teach their mentor more, and therefore we consider this format as a partnership. The mentor is a student who is equal in level to the ward, but with extensive experience in the professional field. A classic example is a first-year student and an undergraduate or graduate student.

On this platform, a significant influence on the mentee is traced, helps him with professional and personal self-determination and contributes to the value and personal content, as well as the correction of the educational trajectory[7].

The goal of this form of mentoring is the successful formation of ideas about the next stage of education, the expansion of professional competencies, as well as the emergence of resources for an informed choice of the future professional development trajectory. The primary objectives of the student-to-student mentoring platform interaction are the following:

* determining educational prospects based on personal potential and knowledge;

* deliberate choice of further professional competencies and learning paths;

* development of "flexible" skills: communication, planning, organization, social networks.

As a result, we will be able to observe the harmonious development of the individual, building professional relationships, awareness of the future profession.

Among the evaluated results we can see:

- raising achievement and improvement of the emotional state of a mentor;

* quantitative and qualitative growth of successfully implemented educational and cultural projects (conferences, scientific articles, etc.);

* increasing the number of students who plan to become mentors in future;

* increase in the number of students enrolled in the areas of training covered by the mentoring program [15].

Portrait of the Mentor participants.

It is a responsible, socially active student with a strong civic and value position, motivated to self-improvement and transformation of the environment. It is a participant of educational, sports, and creative projects. He is enthusiastic and is able to transfer his "creative energy" and interests to others. We also observe a role model in terms of interpersonal relationships, personal self-organization and professional competence [5]. 


\section{Mentored}

Option 1. Passive. Here is a low-motivated student who does not have the desire to independently choose an educational trajectory, is poorly informed about career and educational prospects, and is indifferent to the educational processes within the university and its community.

It is worth emphasizing that a passive mentor is a very rare one, since when choosing a future profession, peculiar selection stages have already been passed and professional competencies have been formulated, which clearly indicate the final goal.

Option 2. Active. It is a motivated student to obtain more information about professional skills, who wants to develop his own skills and acquire professional competencies, but does not have the resource to obtain them.

Possible options of the program.

Variations of role models within the student-to-student platform may vary depending on the needs of the mentee themselves. Given the current experience of educational organizations, the main options may be:

* "successful - unsuccessful" interaction, a classic support option for improving educational outcomes and acquiring self-organization and self-discipline skills;

* interaction "leader - indifferent", psychoemotional and value support with the development of communication, creative, leadership skills, motivation for self-development, education and conscious choice of educational trajectory;

* peer-to-peer interaction, in which skills are exchanged, for example, when the mentor has critical thinking and the mentee has creative thinking; mutual support, active extracurricular activities [14].

The "student-teacher" mentoring platform.

This format offers the interaction of the student directly with the teacher, which activates and launches the professional and personal potential of the mentee, increases his motivation to study and self-realization. At this stage, it is of interest, professionalism and involvement in the profession of mentor, familiarity with the profession is applied, the main goals and objectives, perspectives and percentage of non-realization of the professional competencies are formed.

The goal of this form of mentoring is the successful formation of a mentored conscious approach to the realization of personal potential, which is important for the current day, the growth of the number of people interested in the development of their own talents and skills.

Here you can identify the following main tasks:

* assistance in discovering and evaluating your personal and professional potential;

* raising awareness in matters of career choice, self-determination, personal development, formation of value and life orientations;

* development of leadership, organizational, and communication skills;

* help in gaining experience and familiarity with everyday tasks within the profession.

The result of the correct organization of work will be an increase in the results and increased level of motivation and awareness in matters of education, self-development, selfrealization and professional orientation [9].

Among the evaluated results we can see:

* a conscious approach to the selection of scientific conferences, in the writing of research papers, the choice of the topic of the diploma project;

* numerical growth of successfully implemented and presented results of project activities (together with the mentor);

* increased number of students who plan to become mentors in future;

* increased number of students enrolled in the areas of training covered by the mentoring program; 
* numerical growth of graduates planning employment at regional enterprises.

Portrait of the participants. Mentor.

It is a qualified teacher with a long work experience, an active life position. He has developed communication skills, flexibility in communication, the ability to treat the mentee as an equal in the dialogue and potentially a future colleague. Perhaps, he is a graduate of the same educational organization, a member of the community of grateful graduates.

Mentored. Option 1. Active.

He is a socially active student with special educational needs, motivated to expand the circle of communication, self-improvement, and gain new skills.

Option 2. Passive. Here we find a poorly motivated, disoriented student who does not have the desire to independently choose an educational trajectory, is poorly informed about career and educational prospects, and is indifferent to the processes within an educational organization and its community [6].

When applying for the role of a mentor, regardless of the platforms considered, the mentor must follow the following rules:

- to meet personally with each ward on a regular basis, in order to direct them to study, think about professional competence for solving educational tasks (for example: passing industrial practice, writing scientific papers, preparing for seminars and lectures, defending a diploma);

- $\quad$ to be guided by the basic axiom that the way of thinking of the ward may differ from his way of thinking, and not to suppress his authority;

- to listen carefully and ask open-ended questions to fully understand his point of view;

- $\quad$ to provide specific, high-quality, timely feedback;

- to indicate the strengths and weaknesses of the student, provide both positive (motivational) and negative (constructive) feedback.

In the course of the teacher's activity, special attention is paid to individual tasks that he gives out to students based on his vision of the way of their formation, as well as overcoming difficulties that require particularly careful study. So, if a teacher becomes a mentor for several students, then for each he develops his own set of tasks, taking into account his individual shortcomings in knowledge, skills and abilities. The psychological support function, which is included in the list of duties of a mentor, allows, in addition to discussing the performance of tasks, to discuss the success of the educational process, motivating and interfering factors, fears and doubts that concern the student. Thus, a trusting relationship is established in the "student-teacher" platform, which can make the learning process more effective [4].

As can be seen from the above, mentoring is primarily a strategy of experience, professionalism and clearly built steps for mentors who may hesitate in choosing a future profession. At this stage, there is an understanding of the uniqueness of the mentor as a professional. Every day there is a powerful flow of information that needs to be processed and only a fraction is allowed to work. It is necessary to learn to think in a complex but at the same time extraordinary way.

The results of transformation we can see on the figure1.Blue arrows show advancement and white arrows show possible backsliding. 


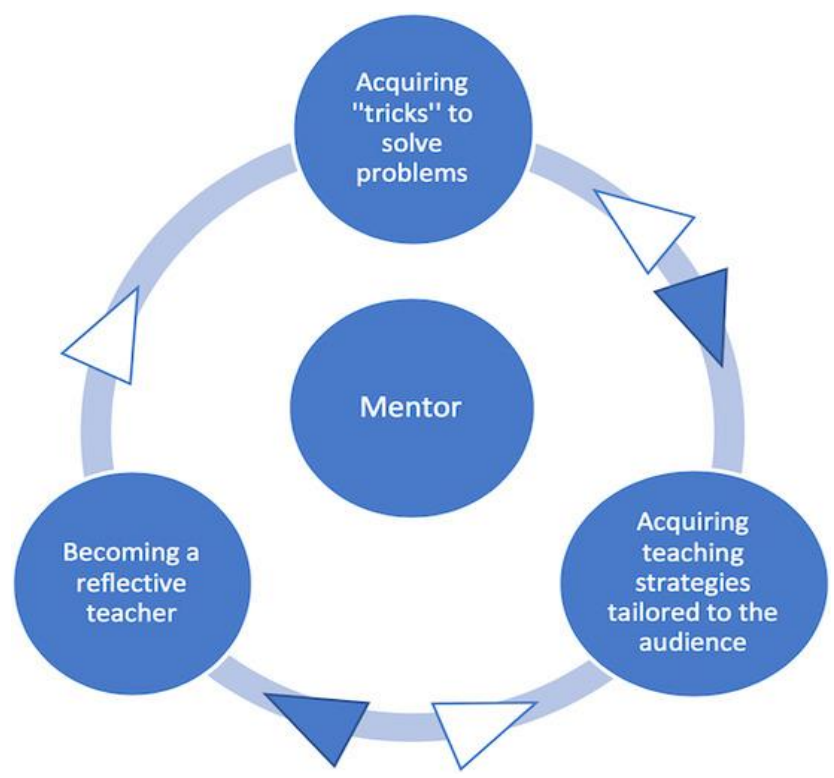

Fig. 1. Cycles of transformation in professional development through faculty mentoring.

\section{Conclusions}

The conducted research allowed the authors of the article:

1) to introduce the student to the educational and corporate culture of the organization, to influence his ability to transform the acquired knowledge;

2) to make systematization of existing professional experience;

3) to obtain the ability to exercise the role of a mentor and thus formulate professorial competencies that are necessary for further growth both within oneself and the mentor;

4) to receive feedback from the mentor, which in future work will contribute to the stimulation of active activity;

5) to increase self-esteem, self-confidence, and feel positive about the work.

Mentoring is an effective tool that promotes professional development, through which all participants in the process can achieve the intended professional success. The correct and logical organization of the system is able not only to transfer professional experience and reveal the full extent of professional competencies, but also to build a completely new concept of professional education [13].

With all of the above, the mentor must not only have extensive experience in teaching the subject, possess technologies for studying, generalizing and disseminating the best pedagogical practices, but also have excellent organizational and communication skills to support motivated students who are determined to cooperation.

Mentoring can also become a suitable method of work both in the course of training, and during the passage of students' training and industrial practice, as well as in time for writing their final qualification work.

\section{References}

1. T.Yu. Tsibizova, O.M. Augustan, D.A. Sergeev, S.A. Mardanov, Modern problems of science and Education 4, 154-159 (2017)

2. V.S. Butenko, O.S. Butenko, Humanities and Social Sciences 4, 248 (2012) 
3. E.A. Chelnokova, R.B. Nabiev, Messenger of Minks University 3(11), 23 (2014)

4. V. Abankina, The attraction of education: 5th Saburov Readings: abstracts 1, 188-199 (2015)

5. V.I. Blinov, E.Yu. Esenina, I.S. Sergeev, Professional education and the Labor market 4(43), 163 (2019)

6. A.G. Gabdullinova, D.D. Orazbekovna, Bulletin of Science and Education 24-4, S78 (2020)

7. A.P. Chernyavskaya, L.N. Nikolaevna, Yaroslavl Pedagogical Bulletin 1, 112 (2020)

8. D.J. Cunningham, Modern Language Journal 100, 484-507 (2016) https://doi.org/10.1111/modl.12332

9. B.J. Irby, I. Mentoring \& Tutoring: Partnership in Learning 23(3), 183-186 (2015)

10. T.A. Volkova, Collection of articles on the results of research of the Department of Philosophy and Sociology for 2018 1, 32-39 (2019)

11. S. Kumar, C. Coe, Am. J. Dist. Educ. 31, 128- 142 (2017)

12. T. Cainand, R. Harris, Educational Active Research 21(3), 343-358 (2013)

13. D.M. Chun, Pedagogies 10, 37- 41 (2015)

14. R. Kern, Modern Language Journal 98, 340-357 (2014) https://doi.org/10.1111/j.15404781.2014.12065.x

15. C. Kramsch, Modern Language Journal 98, 296-311 (2014)

16. T. Vlasova, E. Krasnova, 8th Innovative Technologies in Science and Education, ITSE 2020 210(18012) (2020) 